\title{
2-Aminopurine as a Real-time Probe of Enzymatic Cleavage and Inhibition of Hammerhead Ribozymes
}

\author{
Sarah R. Kirk, Nathan W. Luedtke and Yitzhak Tor* \\ Department of Chemistry and Biochemistry, University of California, San Diego, La Jolla, CA 92093-0358, USA
}

Received 17 January 2001; accepted 29 March 2001

Dedicated to Professor Peter B. Dervan

\begin{abstract}
The design, synthesis and study of internally fluorescent hammerhead (HH) ribozymes, where changes in fluorescence parameters directly reflect the progress of the ribozyme's cleavage chemistry, are described. The approach relies on a HH substrate modified at position 1.1, proximal to the cleavage site, with 2-aminopurine (2AP), an intensely fluorescent adenosine isoster. The incorporation of $2 \mathrm{AP}$, an unnatural nucleoside, does not interfere with the ribozyme folding and catalysis. Since $2 \mathrm{AP}$ is highly sensitive to environmental changes, its fluorescence is dramatically altered upon ribozyme-mediated cleavage of the substrate. This generates a measurable signal that directly reflects the progress of the ribozyme's reaction in real time. Identical pseudo first order rate constants are obtained for $\mathrm{HH}$ constructs using both continuous fluorescence monitoring and radioactive labeling. This rapid and real-time monitoring facilitates the study of ribozyme activity under different conditions (e.g., ionic strength, pH, etc.), and provides a useful assay to rapidly screen potential inhibitors. Three hitherto unknown HH inhibitors are presented and compared to neomycin B and chlortetracycline, two previously studied HH inhibitors. All three new small molecules, neo-acridine, guanidinoneomycin $\mathrm{B}$, and $\left[\Delta-(\text { Eilatin }) \mathrm{Ru}(\text { bpy })_{2}\right]^{2+}$, prove to be better inhibitors than neomycin $\mathrm{B}$ or chlortetracycline. Investigating $\mathrm{HH}$ inhibition under different ionic strengths reveals that the binding of neo-acridine, $[\Delta \text {-(Eilatin)Ru(bpy) }]_{2}^{2+}$, and chlortetracycline to the $\mathrm{HH}$ involves hydrophobic interactions as their RNA affinities are largely unaffected by increasing salt concentrations. In contrast, neomycin B loses more than 50 -fold of its inhibitory ability as the $\mathrm{NaCl}$ concentration is increased from 50 to $500 \mathrm{mM}$. (C) 2001 Elsevier Science Ltd. All rights reserved.
\end{abstract}

\section{Introduction}

Natural and in vitro selected RNA enzymes (ribozymes) are intriguing biopolymers capable of catalyzing a variety of transformations. ${ }^{1}$ Their functional diversity can be attributed to the complex three-dimensional folds that RNA can assume via a multitude of secondary structures and tertiary interactions. ${ }^{2,3}$ Ribozymes, therefore, provide a unique opportunity to correlate RNA structure and function. Valuable information regarding RNA-ligand recognition can be obtained from analyzing ribozyme inhibition by exogenous molecules. ${ }^{4,5}$ Such knowledge is necessary to advance the understanding of RNA-small molecule recognition and for the continued development of small organic molecules as modulators of cellular processes at the RNA level. ${ }^{6,7}$

The hammerhead ribozyme (HH) is one of the best characterized RNA enzymes. ${ }^{8-10} \mathrm{~A}$ wealth of information

*Corresponding author. Tel.: +1-858-534-6401; fax: +1-858-5345383; e-mail: ytor@ucsd.edu regarding its conserved base requirements, kinetics, mechanisms and structure is available. ${ }^{1-15}$ Much less is known, however, about the modulation of enzymatic activity by low molecular weight ligands. ${ }^{16}$ The rapid generation of molecular diversity via combinatorial approaches provides new opportunities to further our understanding of RNA recognition. Large-scale investigations are hampered, however, by the inherent experimental difficulties associated with evaluating ribozyme function. Typically, the RNA substrate is radioactively labeled. Upon annealing to the enzyme component, the cleavage reaction is initiated and sampled over time. The cleaved product is then separated from the fulllength product by polyacrylamide gel electrophoresis and quantified by phosphorimagery. While this method is very sensitive and precise, it is extremely time consuming and therefore not conducive to high throughput analysis of RNA binders. Alternative methods, where fluorescent tags have been appended to the termini of ribozymes have recently been explored. ${ }^{17-21}$ We sought to develop internally fluorescent ribozymes, such that changes in fluorescence parameters would directly reflect the progress of the ribozyme's cleavage chemistry. Here 


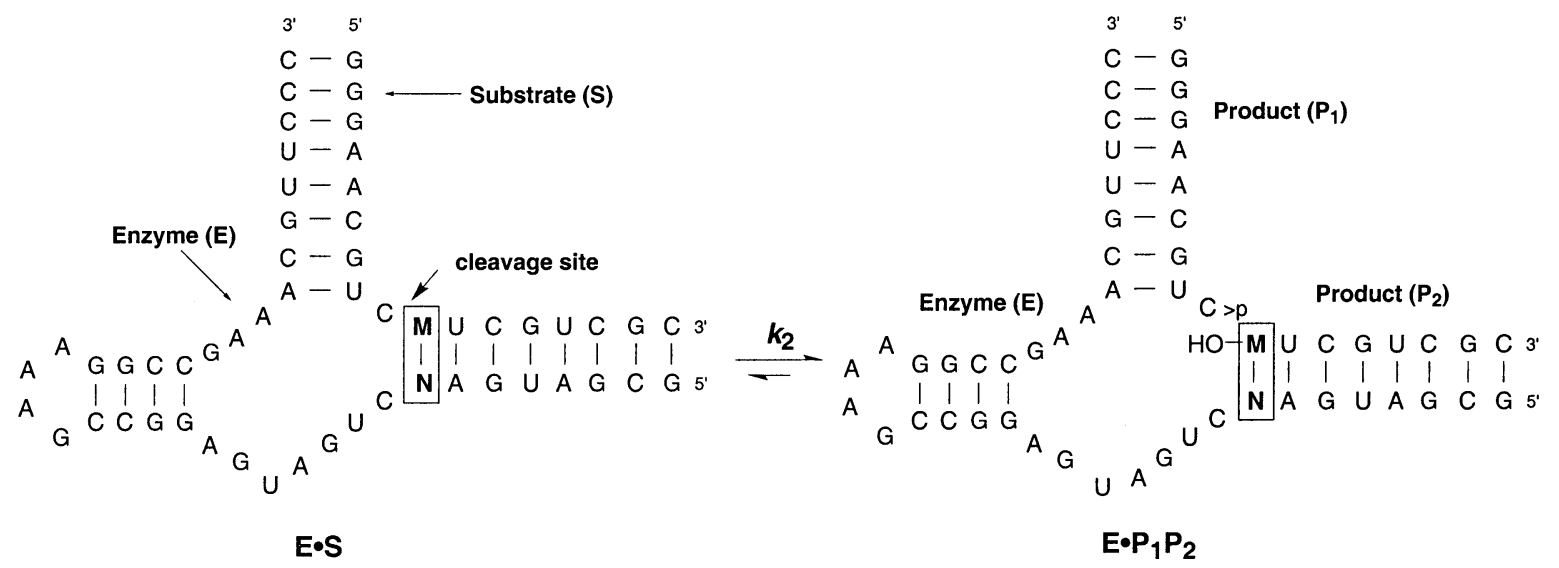

Figure 1. Hammerhead ribozymes and cleavage reaction. HH16 $(\mathrm{M}=\mathrm{G}, \mathrm{N}=\mathrm{C}), \mathrm{HHR} 1(\mathrm{M}=\mathrm{A}, \mathrm{N}=\mathrm{U})$, and $\mathrm{HHR} 2(\mathrm{M}=2 \mathrm{AP}, \mathrm{N}=\mathrm{U})$.

we report the design, synthesis and study of such inherently fluorescent $\mathrm{HH}$ ribozymes, where an intensely fluorescent adenosine isoster, 2-aminopurine (2AP), has been incorporated proximal to the site of cleavage. Since 2AP is highly sensitive to environmental changes, it was anticipated that upon ribozyme-mediated cleavage of the substrate, the photophysical parameters of 2AP would be dramatically altered. In this report we validate the proposed concept and demonstrate the utility of this assembly for the study of ribozyme activity and inhibition.

\section{Design}

The hammerhead ribozyme HH16, a small and highly active RNA enzyme, ${ }^{8}$ has been chosen as the primary system for the development of reporting ribozymes. Strategically modified $\mathrm{HH}$ ribozymes, with $2 \mathrm{AP}$ at position ' $\mathrm{M}$ ' and uridine at position ' $\mathrm{N}$ ', have been selected as the prototypical assembly (Fig. 1). The following criteria were taken into consideration in designing these inherently fluorescent ribozymes. The modified nucleotide is not among the conserved core of nucleotides. ${ }^{8} 9$ It is known that any base pair can be accommodated at the modification positions. ${ }^{9}$ Since 2AP forms Watson-Crick-type hydrogen bonds with uridine resulting in a base pair that is isostructural to $\mathrm{A}=\mathrm{U}$, a negligible structural perturbation is anticipated (Fig. 2). The modification position is centrally located and adjacent to the cleavage site. Upon phosphodiester cleavage, the base stacking, solvation, and dynamics of 2AP are likely to change substantially. ${ }^{22}$ Since the photophysical properties of $2 \mathrm{AP}$ are known to change in response to changes in its local environment, ${ }^{23-26}$ it is expected that continuous fluorescence measurements can be used to monitor the progress of ribozyme-mediated cleavage in real time. ${ }^{27}$

\section{Results}

\section{Proof of concept}

$5^{\prime}-{ }^{32} \mathrm{P}$-labeled 17 -mer $\mathrm{HH}$ substrates that contain a $2 \mathrm{AP}$, an $\mathrm{A}$ or a $\mathrm{G}$ at position $\mathrm{M}$, proximal to the cleavage site (Fig. 1), are annealed to a corresponding 38 mer enzyme in $50 \mathrm{mM}$ Tris- $\mathrm{HCl}$, $\mathrm{pH} 7.0$ in the presence of $\mathrm{NaCl}(200 \mathrm{mM})$ and $\mathrm{MgCl}_{2}(10 \mathrm{mM})$, and tested for their cleavage rate (Fig. 3). Under these single turnover conditions, the following pseudo first order rate constants $k_{2}$ are obtained: $0.22 \pm 0.01 \mathrm{~min}^{-1}$ (for $\mathrm{G} \equiv \mathrm{C}$ ), $0.23 \pm 0.02 \mathrm{~min}^{-1}$ (for $2 \mathrm{AP}=\mathrm{U}$ ), and $0.39 \pm 0.03 \mathrm{~min}^{-1}$ (for $\mathrm{A}=\mathrm{U}$ ). The reaction of the $2 \mathrm{AP}$-containing ribozyme HHR2 is monitored by fluorescence spectroscopy under the same reaction conditions. Continuous recording of the fluorescence at $370 \mathrm{~nm}$ upon excitation at $305 \mathrm{~nm}$ reveals a nearly 3 -fold increase in emission over a period of $20 \mathrm{~min}$. Analysis of these data yields a $k_{2}$ value of $0.23 \pm 0.01 \mathrm{~min}^{-1}$. Normalized data for HHR2, generated using the radioactively- and fluorescence-monitored experiments, are overlaid (Fig. 4). An excellent correlation is obtained.

To support the generality of our approach and its applicability to related ribozymes of a markedly different activity, a mutant enzyme has been designed (Fig. 5). This 35-mer is a truncated version of the 38-mer enzyme, where the number of base pairs in stem I is reduced from eight to five. Additionally, two wobble<smiles></smiles>

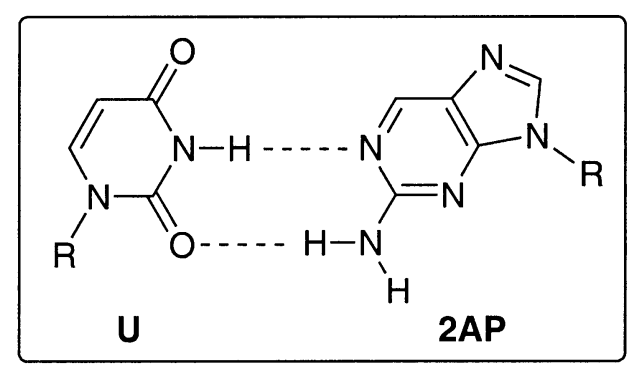

Figure 2. The isostructural $\mathrm{U}-\mathrm{A}$ and $\mathrm{U}-2 \mathrm{AP}$ base pairs. 

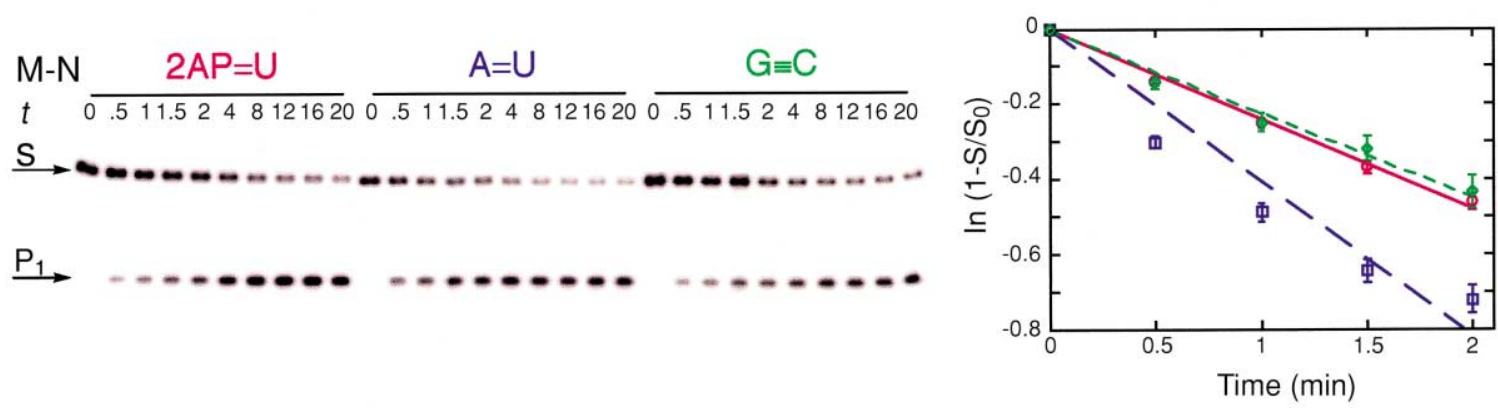

Figure 3. Left: Cleavage reactions of HHR2, HHR1, and HH16 as determined by radioactive labeling of substrate strand. S and $\mathrm{P}_{1}$ indicate substrate and product strands, respectively (Fig. 1). All reactions were conducted at $37^{\circ} \mathrm{C}$ and contained $1.85 \mu \mathrm{M}$ substrate (including a trace of $5^{\prime}-32 \mathrm{P}$ labeled material), $10.3 \mu \mathrm{M}$ enzyme, $50 \mathrm{mM}$ Tris $\mathrm{pH} 7.0,200 \mathrm{mM} \mathrm{NaCl}$, and $10 \mathrm{mM} \mathrm{MgCl}$. Cleavage reactions were quenched at the given times $(t$ in min) and resolved by $20 \%$ PAGE. Right: Initial kinetics of HHR2 (O), HHR1 ( $\square)$, and HH16 ( $)$. The pseudo first order rate constant, $k_{2}$, of the cleavage reactions are determined as the slope of $\ln$ (fraction cleaved) versus time.

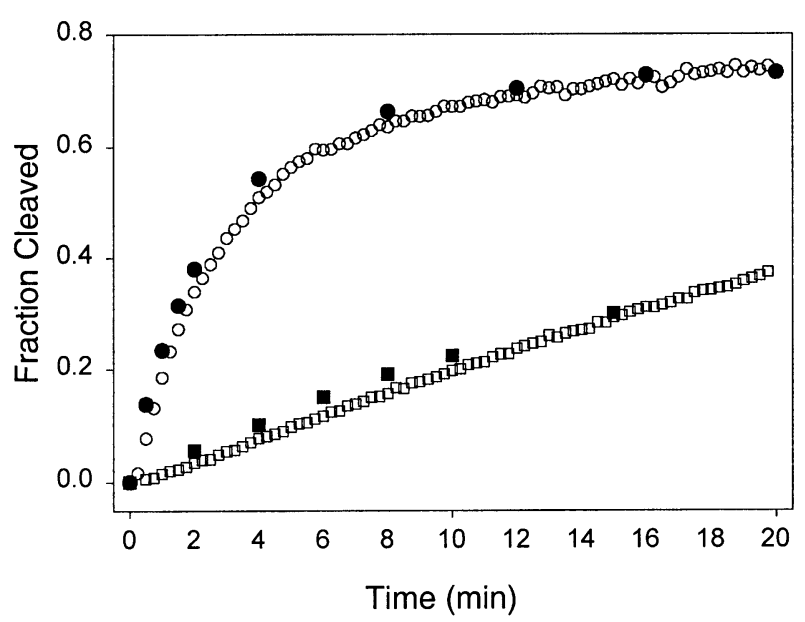

Figure 4. An overlay of ribozyme mediated cleavage curves derived from HHR2 fluorescence $(\bigcirc)$, and radioactive data $(\bullet)$, as well as from HHR4 fluorescence $(\square)$ and radioactive $(\boldsymbol{\square})$ data.

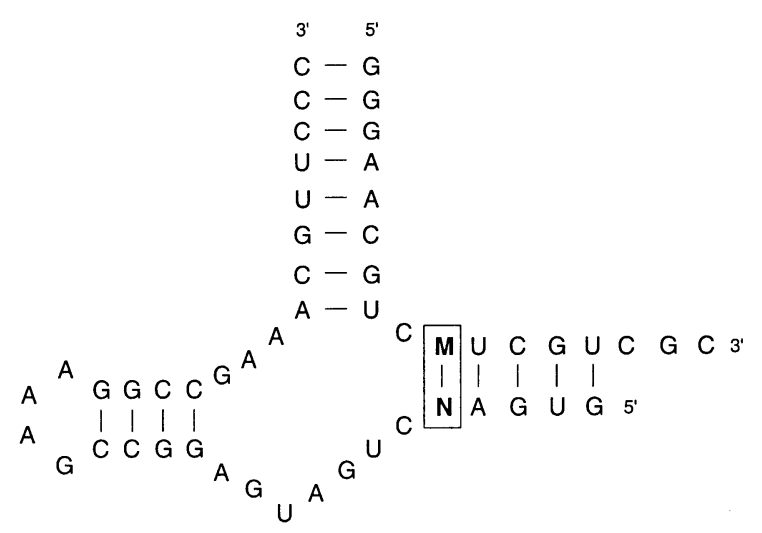

Figure 5. Truncated 35-mer hammerhead ribozyme. HHR3 $(\mathrm{M}=\mathrm{A}$, $\mathrm{N}=\mathrm{U})$, and HHR4 $(\mathrm{M}=2 \mathrm{AP}, \mathrm{N}=\mathrm{U})$.

$\mathrm{G} \bullet \mathrm{U}$ base pairs are generated upon enzyme-substrate complex formation. Single turnover experiments using ${ }^{32} \mathrm{P}$-labeled substrates show that this enzyme cleaves the A- and 2AP-containing substrates with pseudo first-order rate constants $k_{2}$ of 0.019 and $0.024 \mathrm{~min}^{-1}$, respectively. Fluorescence monitoring of the cleavage reaction of the truncated construct HHR4 yields a curve that closely matches the data obtained by radiolabeling (Fig. 4).

\section{Effects of ionic strength and $\mathrm{pH}$ on cleavage rate}

Cleavage of the fluorescent 2AP-containing ribozyme HHR2 is monitored at various salt concentrations. The initial rate constants determined by fluorescence in the presence of $50,100,200$ and $500 \mathrm{mM} \mathrm{NaCl}$ are $0.30 \pm .07,0.31 \pm .01,0.23 \pm .01$, and $0.20 \pm .04 \mathrm{~min}^{-1}$, respectively. At $2 \mathrm{M} \mathrm{NaCl}$, substrate cleavage is completely abolished. Changes in $\mathrm{pH}$ also affect ribozyme activity. Cleavage is accelerated when the basicity of the reaction medium is increased. When the $\mathrm{pH}$ is increased from 6.5 to 8.5 in increments of $0.5 \mathrm{pH}$ units, the following rate constants are obtained: $0.14 \pm 0.01 \mathrm{~min}^{-1}$ (6.5), $0.23 \pm 0.01 \mathrm{~min}^{-1}$ (7.0), $0.52 \pm 0.08 \mathrm{~min}^{-1}$ (7.5), $0.8 \pm 0.1 \mathrm{~min}^{-1}(8.0)$, and $0.9 \pm 0.1 \mathrm{~min}^{-1}(8.5)$.

\section{Ribozyme inhibition by small molecules}

Five ligands are studied for their effect on ribozyme activity: neomycin B, neo-acridine, guanidino-neomycin B, $\left[\Delta-(\text { Eilatin }) \mathrm{Ru}(\mathrm{bpy})_{2}\right]^{2+}$, and chlortetracyline (Fig. 6). Cleavage reactions are monitored in the presence of increasing ligand concentrations and at three different salt concentrations $(50,200$, and $500 \mathrm{mM} \mathrm{NaCl})$. Figure 7 shows a representative example of raw experimental data. Table 1 lists the corresponding IEC $_{50}$ values, defined as the inhibitor concentration at which the initial rate of cleavage is decreased by a factor of two. Experiments conducted with a radioactively-labeled substrate confirmed that IEC $_{50}$ values correlate well with the concentrations required for diminishing the ribozyme pseudo first order rate constants to $0.5 \times k_{2}$.

\section{Discussion}

\section{Effect of 2AP incorporation on cleavage rates}

All $\mathrm{HH}$ constructs are active and undergo efficient phosphodiester bond cleavage (Fig. 3). The cleavage rate for the $2 \mathrm{AP}=\mathrm{U}$ construct $(\mathrm{HHR} 2)$ is identical to the 'wild type' construct (HH16) while the $\mathrm{A}=\mathrm{U}$ construct is almost two-fold faster. Similar rate enhancements have also been observed by others. ${ }^{28}$ The truncated ribozymes shown in Figure 5 are significantly slower than the corresponding longer constructs, but 


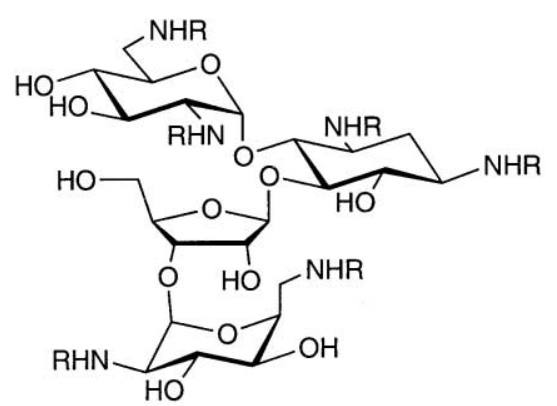

$\begin{array}{ll}\text { Neomycin B } & \mathrm{R}=\mathrm{H} \\ \text { Guanidino-neomycin B } & \mathrm{R}=(\mathrm{C}=\mathrm{NH}) \mathrm{NH}_{2}\end{array}$

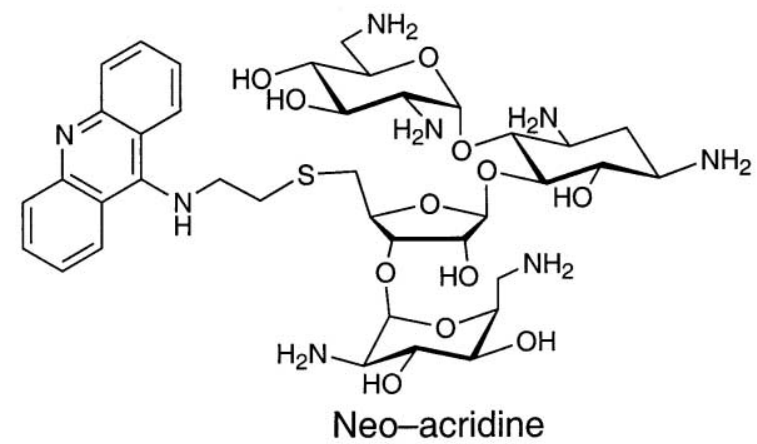

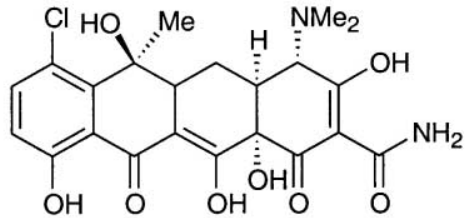

Chlortetracycline

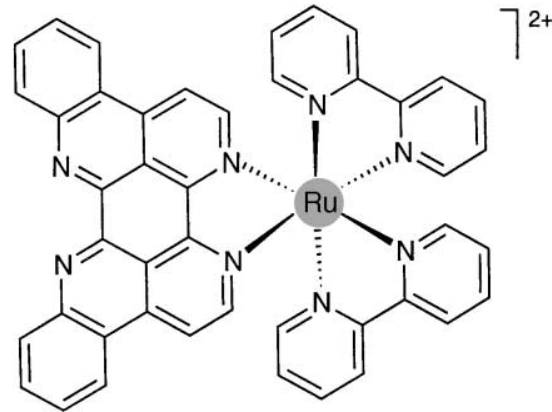

$\left[\Delta-(\text { Eilatin }) \mathrm{Ru}(\mathrm{bpy})_{2}\right]^{2+}$

Figure 6. Structures of HH inhibitors.

initial rates derived for the ribozymes containing $\mathrm{A}=\mathrm{U}$ (HHR3) and $2 \mathrm{AP}=\mathrm{U}(\mathrm{HHR} 4)$ are very similar. These results indicate that the incorporation of $2 \mathrm{AP}$, an unnatural nucleoside, does not interfere with the ribozyme folding and catalysis.

\section{Comparison of 'standard' and fluorescence derived rate constants}

The initial rate constants obtained by continuously monitoring 2AP's increase in fluorescence quantum yield are found to be the same as those obtained by radiolabeling. The two cleavage curves are essentially identical for both the highly active as well as the slower ribozymes (Fig. 4). These results validate our design and confirm that a strategic placement of a reporter nucleoside adjacent to the ribozyme's cleavage site provides an effective approach to continuously follow cleavage kinetics.

\section{Origin of fluorescence emission enhancement}

Experiments with individually synthesized cleavage products indicate that the 3 -fold increase in 2AP fluorescence emission, upon cleavage, is not dependent on the dissociation of product P2 from the enzyme (data not shown). Based upon the crystal structure of the cleaved-product $\mathrm{HH}$ ribozyme, ${ }^{29}$ position M (Fig. 1) becomes more solvent exposed upon substrate cleavage. Increased solvation, upon cleavage, is likely the origin of the emission enhancement of $2 \mathrm{AP} .{ }^{24}$

\section{Modulation of cleavage}

The presence of a fluorescent reporting nucleoside provides a facile method for the study of salt and $\mathrm{pH}$ effects on cleavage rate. Increasing the ionic strength from 50 to $500 \mathrm{mM} \mathrm{NaCl}$ slows down the ribozyme by approximately $50 \%$. At $2 \mathrm{M} \mathrm{NaCl}$ the ribozyme is completely inactive. This suggests that $\mathrm{Na}^{+}$can compete with $\mathrm{Mg}^{+2}$ ions for essential folding or catalytic sites on the hammerhead. Increasing the $\mathrm{pH}$ from 6.5 to 8.5 results in approximately 6-fold enhancement of the ribozyme initial rate. This observation is consistent with the trend found by others. ${ }^{30}$ It is worth noting that this rate enhancement prohibits the accumulation of reliable data using alternative techniques (such as radiolabeling) since manual sampling becomes more challenging and user-dependent.

\section{Inhibition of cleavage by small molecules}

The 2AP-containing ribozymes provide a useful assay to rapidly screen potential inhibitors. Three representative small molecules are selected from our prior studies of RNA ligands, ${ }^{31-33}$ and compared to two previously studied inhibitors: neomycin B and chlortetracycline. ${ }^{34,35}$ These new inhibitors; neo-acridine, guanidino-neomycin $\mathrm{B}$, and $[\Delta$-(Eilatin $\left.) \mathrm{Ru}(\text { bpy })_{2}\right]^{2+}$, prove to be more potent cleavage inhibitors than neomycin B and chlortetracycline under all conditions surveyed. 
To illustrate how fundamental knowledge regarding ribozyme catalysis can be rapidly accumulated using fluorescent constructs, the effects of ionic strength on inhibitory activities were determined (Table 1). Each inhibitor is analyzed under three different ionic strengths. Neomycin B is known to bind to RNA via

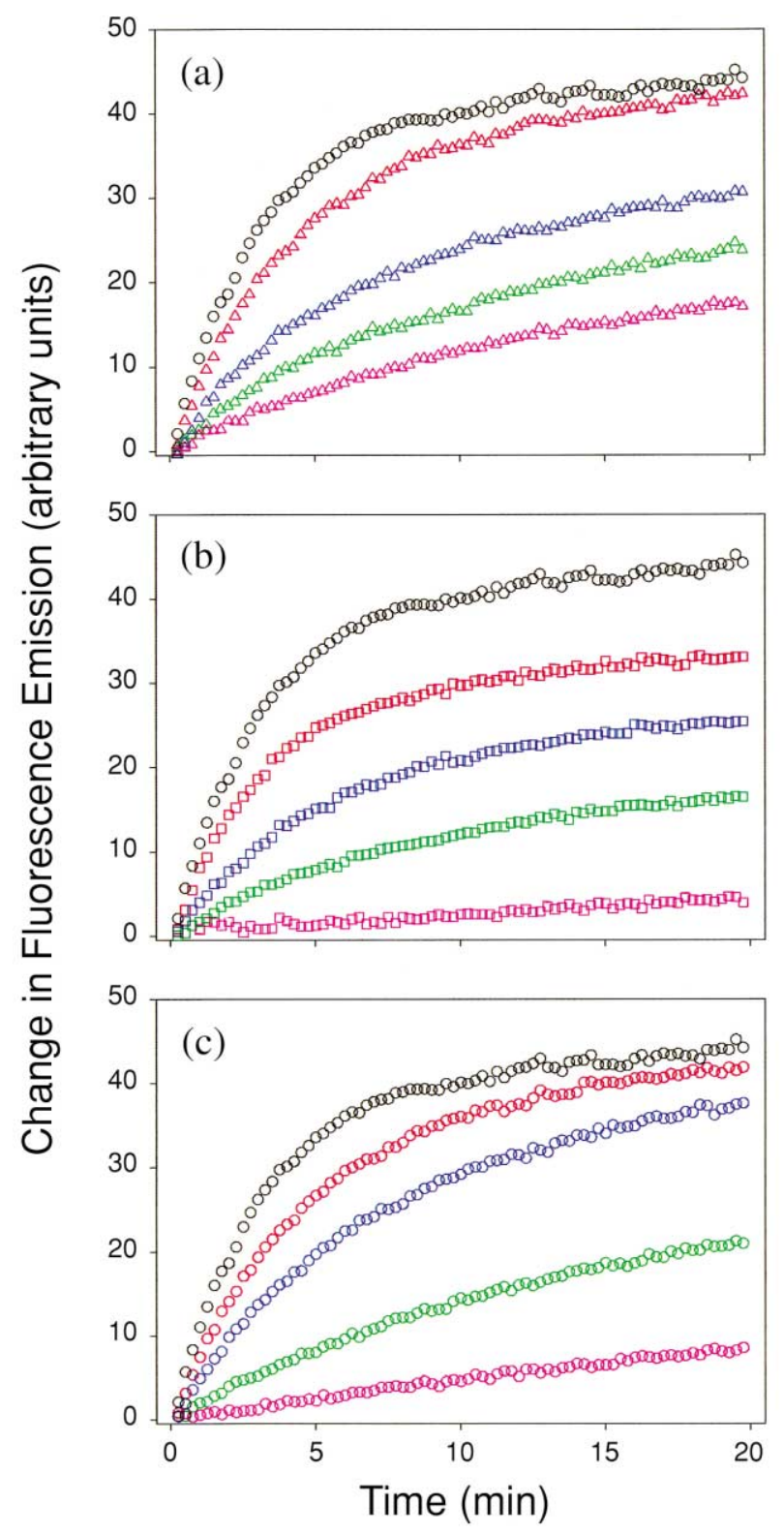

Figure 7. HHR2 cleavage curves in the presence of three inhibitors at $200 \mathrm{mM} \mathrm{NaCl}$ : (a) neomycin B at $0(\mathrm{O}), 100(\triangle), 250(\triangle), 500(\triangle)$, and $1000(\triangle) \mu \mathrm{M}$, respectively; (b) neo-acridine at $0(\mathrm{O}), 3(\square), 7$ ( $\square$ ), $10(\square)$, and $50(\square) \mu \mathrm{M}$, respectively; and (c) guandidino-neomycin B at $0(\mathrm{O}), 5(\mathrm{O}), 10(\mathrm{O}), 25(\mathrm{O})$, and $50(\mathrm{O}) \mu \mathrm{M}$, respectively. HHR2 excitation is at $305 \mathrm{~nm}$ and emission is monitored at $370 \mathrm{~nm}$. electrostatic interactions. ${ }^{36,37}$ Consequently, it shows the highest sensitivity to changes in salt concentration. As the $\mathrm{NaCl}$ concentration is increased from 50 to $500 \mathrm{mM}$, neomycin B loses more than 50 -fold of its inhibitory activity. Guanidino-neomycin B is also affected by the change in salt concentration but to a much lesser extent. Neo-acridine is thought to interact with RNA through both electrostatic and intercalative interactions. ${ }^{31}$ However, its relative insensitivity to ionic strength changes hints that intercalation may be the dominant energetic driving force for $\mathrm{HH}$ binding. The inhibition activities of $\left[\Delta \text {-(Eilatin) } R u(b p y)_{2}\right]^{2+}$ and chlortetracycline are unaffected by increasing salt concentrations. This indicates that these compounds bind the $\mathrm{HH}$ exclusively through hydrophobic interactions. Interestingly, neomycin B is a better inhibitor than chlortetracycline at low salt concentrations; however, the opposite is observed at high salt concentrations. These observations indicate that inhibitory effects exhibited by small molecules are often highly sensitive to the conditions under which ribozyme cleavage is monitored.

\section{Conclusions}

The results outlined above demonstrate that incorporating $2 \mathrm{AP}$ next to the cleavage site in the $\mathrm{HH}$ ribozyme provides a powerful method for the study of ribozyme catalysis and inhibition. To our knowledge this is the first time an internal fluorescent base has been utilized to monitor RNA cleavage chemistry. This approach possesses three important advantages over more traditional techniques: (1) results are generated much more rapidly as cleavage is followed in real-time, (2) human errors are minimized as continuous time measurements replace sampling, and (3) it is amenable to automation and high throughput screening. We anticipate that rapid analysis of low molecular weight ligands, under various conditions, will substantially advance the generation of new structure-activity relationships and our understanding of RNA recognition.

\section{Experimental}

\section{RNA oligonucleotides}

The $\mathrm{HH}$ substrates were prepared on a Milligen Cyclone Plus DNA synthesizer using standard protocols for RNA synthesis. The 2'-TBDMS protected 2-aminopurine ribonucleoside phosphoramidite was prepared from 6-thioguanosine according to Eckstein and coworkers, ${ }^{38}$ and introduced site-specifically by manual coupling. ${ }^{39}$ Additional RNA sequences have been purchased from Dharmacon. All deprotected RNA

Table 1. IEC $_{50}$ values $(\mu \mathrm{M})$ for inhibitors under three different ionic strengths

\begin{tabular}{lccccr}
\hline $\mathrm{NaCl}(\mathrm{mM})$ & Neomycin B & Neo-acridine & Guanidino-neomycin B & {$[\Delta \text {-(Eilatin) Ru(bpy) }]^{2+}$} & $\mathrm{Chlortetracyline}$ \\
\hline 50 & $45 \pm 10$ & $4.5 \pm 1$ & $7 \pm 2$ & $7 \pm 3$ & $10 \pm 2$ \\
200 & $200 \pm 50$ & $5.5 \pm 2$ & $7 \pm 2$ & $5 \pm 2$ & $100 \pm 30$ \\
500 & $>2000$ & $7 \pm 2$ & $55 \pm 10$ & $100 \pm 30$ \\
\hline
\end{tabular}


sequences were purified by preparative $20 \%$ denaturing polyacrylamide gel electrophoresis. The gels were visualized by UV shadowing and the desired bands excised from the gel and extracted with Tris-borateEDTA (TBE) buffer pH $8.3(90 \mathrm{mM}$ Tris, $90 \mathrm{mM}$ boric acid, $1 \mathrm{mM}$ EDTA) for $24-36 \mathrm{~h}$. The RNA was concentrated by ethanol precipitation and stored in sterilized water. Concentrations of all $\mathrm{HH}$ substrates were determined at $260 \mathrm{~nm}$ under denaturing conditions $(6 \mathrm{M}$ Urea, $100 \mathrm{mM}$ Tris- $\mathrm{HCl}$, pH 7.5) by absorption spectroscopy (Hewlett Packard 8452A diode array spectrophotometer) using the following molar extinction coefficients: 15400 (A), 11700 (G), 10100 (U), 7300 (C), and 1000 (2AP). The substrate was $5^{\prime}-{ }^{32} \mathrm{P}$ labeled with $\left[\gamma^{32} \mathrm{P}\right] \mathrm{ATP}$ and T4 polynucleotide kinase. ${ }^{40}$ Labeled material was purified by gel electrophoresis on $20 \%$ polyacrylamide $/ 8 \mathrm{M}$ urea gels, extracted with $200 \mathrm{mM}$ KOAc, $10 \mathrm{mM}$ EDTA (pH 5.45) for $12 \mathrm{~h}$ at $4{ }^{\circ} \mathrm{C}$, and ethanol precipitated in the presence of glycogen as a carrier. The HH16 enzymes were synthesized by 'runoff' in vitro transcription using T7 RNA polymerase and synthetic DNA template as described by Uhlenbeck. ${ }^{41}$ Transcription products were purified by denaturing gel electrophoresis and processed as described above.

\section{Ribozyme reaction conditions}

All cleavage reactions were conducted in a reaction volume of $70 \mu \mathrm{L}$ at $37^{\circ} \mathrm{C}$ in a buffer containing $50 \mathrm{mM}$ Tris- $\mathrm{HCl}(\mathrm{pH}$ 6.5-8.5) and $\mathrm{NaCl}(0-500 \mathrm{mM})$. Buffered solutions of the substrate and enzyme were denatured separately by heating to $90^{\circ} \mathrm{C}$ for $90 \mathrm{~s}$ and cooled to room temperature over $10 \mathrm{~min}$ to allow for refolding. $\mathrm{MgCl}_{2}(10 \mathrm{mM})$ and inhibitors (when appropriate) were added to both the enzyme and substrate and allowed to equilibrate at $37^{\circ} \mathrm{C}$ for $5 \mathrm{~min}$. The cleavage reaction was then initiated by manually mixing the substrate with the enzyme in a heat block or a fluorescence cuvette preheated to $37^{\circ} \mathrm{C}$. For all experiments the final concentration of substrate and enzyme is 1.85 and $10.3 \mu \mathrm{M}$, respectively.

\section{Radioactive assay}

Experiments with radioactively-labeled substrates contained a trace of $5^{\prime}-{ }^{32} \mathrm{P}$ labeled substrate. For initial data points (time $=0), 2 \mu \mathrm{L}$ of the substrate were removed immediately prior to starting the reaction. Following initiation of the reaction, $4 \mu \mathrm{L}$ aliquots were removed at designated time periods and quenched with $12 \mu \mathrm{L}$ of a urea containing loading buffer $(8 \mathrm{M}$ urea, $50 \mathrm{mM}$ EDTA, $0.1 \times$ TBE, $0.14 \mathrm{nM}$ bromophenol blue, and $0.19 \mathrm{nM}$ xylene cyanol FF). The tubes were heated to $90{ }^{\circ} \mathrm{C}$ for $90 \mathrm{~s}$ and loaded on a $20 \%$ polyacrylamide $/ 8 \mathrm{M}$ urea gel. Gels were quantified on a Molecular Dynamics Phosphorimager ${ }^{\mathrm{TM}} 445$ SI and analyzed with Imagequant $^{\mathrm{TM}}$ software (Molecular Dynamics).

\section{Fluorescence experiments}

All fluorescence measurements were conducted on a Perkin Elmer LS50B Luminescence Spectrometer with an attached temperature controlled unit. Experiments with the 2AP containing substrate were conducted in a masked micro fluorescence cuvette thermoregulated at $37^{\circ} \mathrm{C}$. Fluorescence emission measurements were taken by exciting the samples at $305 \mathrm{~nm}$ and monitoring emission at $370 \mathrm{~nm}$. As a control, selected samples were resolved on a $20 \%$ denaturing polyacrylamide gel and visualized by staining (Stains-all ${ }^{\circledR}$ ) to confirm the presence of the expected cleavage products and the absence of non-specific RNA degradation. To rule out non-specific substrate hydrolysis and photochemical degradation upon continuous irradiation, control experiments were run in the absence of $\mathrm{MgCl}_{2}$; no detectable changes in emission were observed.

\section{Data analysis}

When cleavage is conducted under single-turnover conditions, the pseudo first order rate constant $k_{2}$ can be easily extracted from measurements of the ribozyme's initial rate of cleavage. ${ }^{27}$ Since the cleavage reaction occurs within the hammerhead complex, it can be treated as a first order intramolecular reaction. Rate constants $\left(k_{2}\right)$ were calculated as the slope of $\ln \left(1-\mathrm{S} / \mathrm{S}_{0}\right)$ versus time, where $S / S_{0}$ is the fraction of cleaved substrate. For experiments utilizing a radioactively labeled substrate, $\mathrm{S} / \mathrm{S}_{0}$ was determined by dividing the amount of cleaved substrate by the sum of the full length and cleaved substrate. To confirm that pseudo first order analysis of the data is justified, enzyme-substrate association was monitored (in the absence of $\mathrm{MgCl}_{2}$ ) by measuring the decrease in fluorescence emission of the 2AP containing substrate with increasing enzyme concentration. These titrations confirm that greater than $95 \%$ of the substrate is bound by the enzyme for all constructs under all ionic strengths reported (data not shown). Furthermore, upon mixing the enzyme with the substrate (in the absence of $\mathrm{MgCl}_{2}$ ) the observed association is faster than the 'dead time' of the kinetic experiments (less than $20 \mathrm{~s}$ ). These observations confirm that, under these conditions, the influence of enzymesubstrate association rate on the observed cleavage rates can be neglected. The initial point $\left(y_{0}\right)$ of the fluorescently-monitored reactions was derived by fitting the raw data to an exponential curve fit $y=y_{0}+\mathrm{a}\left(1-\mathrm{e}^{-b x}\right)$, where $y=$ fluorescence intensity, $a=$ the rise, $b=$ the rate and $x=$ time. The end point $(f)$ was separately determined by measuring the fluorescence of individually synthesized cleavage products (P1 and $\mathrm{P} 2)$ annealed to the enzyme $(E)$ under the same reaction conditions; hence $\mathrm{S} / \mathrm{S}_{0}$ (fraction cleaved $)=\left(y-y_{0}\right) /\left(f-y_{0}\right)$. Using this method the percent cleavage after $20 \mathrm{~min}$ was essentially the same for the radioactive- and fluorescencegenerated data; both reactions were found to reach $75 \%$ of completion. ${ }^{42}$ The IEC $_{50}$ values (concentration of inhibitor leading to a $50 \%$ reduction of ribozyme cleavage rate) were determined by measuring the concentration of inhibitor needed to decrease the initial slope (between 30 seconds and two $\mathrm{min}$ ) by $50 \%{ }^{43}$ The IEC $_{50}$ values are used only for comparative purposes and are not to be confused with actual $k_{2}$ values. 


\section{Acknowledgements}

The authors thank Professor Jack Kyte for planting the seed that led to the evolution of this project. We are grateful to the National Institutes of Health (AI 47673) for generous support and the Universitywide AIDS Research Program of the University of California for a doctoral fellowship to N.W.L. (D00-SD-017). We thank Professor Moshe Kol for his kind gift of eilatin-containing complexes.

\section{References and Notes}

1. Tanner, N. K. FEMS Microbiology Rev. 1999, 23, 257.

2. Chastain, M.; Tinoco, I., Jr. Prog. Nucl. Acid Res. 1991, 41, 131.

3. Ferré-D’Amaré, A. R.; Doudna, J. A. Annu. Rev. Biophys. Mol. Struct. 1999, 28, 57.

4. Stage, T. K.; Hertel, K. J.; Uhlenbeck, O. C. $R N A$ 1995, 1, 95.

5. Wang, H.; Tor, Y. J. Am. Chem. Soc. 1997, 119, 8734.

6. Werstuck, G.; Green, M. R. Science 1998, 282, 296.

7. Tor, Y. Angew. Chem., Int. Ed. 1999, 38, 1579.

8. Uhlenbeck, O. C. Nature 1987, 328, 596.

9. Vaish, N. K.; Kore, A. R.; Eckstein, F. Nucl. Acids Res. 1998, 26, 5237.

10. Birikh, K. R.; Heaton, P. A.; Eckstein, F. Eur. J. Biochem. 1997, $245,1$.

11. Verma, S.; Vaish, N. K.; Eckstein, F. Curr. Opin. Chem. Biol. 1997, 1, 532.

12. Wedekind, J. E.; McKay, D. B. Annu. Rev. Biophys. Biomol. Struct. 1998, 27, 475 .

13. Stage-Zimmermann, T. K.; Uhlenbeck, O. C. $R N A$ 1998, 4,875 .

14. Zhou, D. M.; Taira, K. Chem. Rev. 1998, 98, 991.

15. Amarzguioui, M.; Prydz, H. Cell. Mol. Life Sci. 1998, 54, 1175.

16. Michael, K.; Tor, Y. Chem. Eur. J. 1998, 4, 2091.

17. Tuschl, T.; Gohlke, C.; Jovin, T. M.; Westhof, E.; Eckstein, F. Science 1994, 266, 785.

18. Bassi, G. S.; Murchie, A. I. H.; Walter, F.; Clegg, R. M.; Lilley, D. M. J. EMBO J. 1997, 16, 7481.

19. Jenne, A.; Gmelin, W.; Raffler, N.; Famulok, M. Angew. Chem., Int. Ed. 1999, 38, 1300.

20. Singh, K. K.; Parwaresch, R.; Krupp, G. RNA 1999, 5, 1348.

21. Llano-Sotelo, B.; Chow, C. S. Bioorg. Med. Chem. Lett. 1999, 9, 213.

22. Xu, D.; Evans, K. O.; Nordlund, T. M. Biochemistry 1994, 33, 9592 .
23. Helmen, A.; Norden, B.; Albinsson, B. J. Am. Chem. Soc. 1997, 119, 3114.

24. Ward, D. C.; Reich, E.; Stryer, L. J. Biol. Chem. 1969, 244, 1228 .

25. Menger, M.; Tuschl, T.; Eckstein, F.; Porschke, D. Biochemistry 1996, 35, 14710.

26. Lacourciere, K. A.; Stivers, J. T.; Marino, J. P. Biochemistry 2000, 39, 5630 .

27. For the HH16, substrate cleavage is strongly favored over ligation, allowing simple interpretation of observed kinetics. See: Fedor, M. J.; Uhlenbeck, O. C. Biochemistry 1992, 31, 12042.

28. Clouet-d'Orval, B.; Uhlenbeck, O. C. Biochemistry 1997, 36,9087 .

29. Murray, J. B.; Szoke, H.; Szoke, A.; Scott, W. G. Mol. Cell 2000, 5, 279.

30. Hertel, K. J.; Uhlenbeck, O. C. Biochemistry 1995, 34, 1744.

31. Kirk, S. R.; Luedtke, N. W.; Tor, Y. J. Am. Chem. Soc. 2000, 122, 980 .

32. Luedtke, N. W.; Baker, T. J.; Goodman, M.; Tor, Y. J. Am. Chem. Soc. 2000, 122, 12035.

33. Luedtke, N. W.; Tor, Y. Angew. Chem., Int. Ed. 2000, 39, 1788.

34. Clouet-d'Orval, B.; Stage, T. K.; Uhlenbeck, O. C. Biochemistry 1995, 34, 11186.

35. Murray, J. B.; Arnold, J. R. P. Biochem. J. 1996, 317, 855.

36. Hermann, T.; Westhof, E. J. Mol. Biol. 1998, 276, 903.

37. Tor, Y.; Hermann, T.; Westhof, E. Chem. Biol. 1998, 5, R277.

38. Tuschl, T.; Ng, M. M. P.; Pieken, W.; Benseler, F.; Eckstein, F. Biochemistry 1993, 32, 11658.

39. Doudna, J. A.; Szostak, J. W.; Rich, A.; Usman, N. J. Org. Chem. 1990, 55, 5547.

40. Sambrook, J.; Fritsch, E. F.; Maniatis, T. Molecular Cloning, 2nd ed.; Cold Springs Harbor Laboratory Press: New York, 1989.

41. Uhlenbeck, O. C.; Milligan, J. F. Methods in Enzymology 1989, $180,51$.

42. Incomplete cleavage is observed by other groups and is likely related to misfolding (see ref 13).

43. In the presence of most inhibitors (including neomycin $\mathrm{B}$, guanidino-neomycin $\mathrm{B}$ and $\left.\left[\Delta \text {-(Eilatin) } \mathrm{Ru}(\mathrm{bpy})_{2}\right]^{2+}\right)$, ribozyme-mediated cleavage reactions eventually reach $75 \%$ completion (which is the typical end point of the uninhibited $\mathrm{HH}$ constructs). Some inhibitors (including neo-acridine and, albeit irregularly, chlotetracycline) prevent the ribozyme from reaching this end point. It is possible that these inhibitors irreversibly misfold a percentage of the hammerhead constructs. IEC $_{50}$ values are determined at early time points (between $30 \mathrm{~s}$ and $2 \mathrm{~min}$ ) to minimize the impact of different end points on our analysis. 